\title{
Idiopathic granulomatous mastitis with erythema nodosum and polyarthritis
}

\author{
J. Alungal, M.C. Abdulla, R. Narayan \\ Department of General Medicine, Muslim Educational Society Medical College, Malappuram, India
}

\begin{abstract}
SUMMARY
A 25 year-old woman presented with a painful mass in the left breast, polyarthritis and erythema nodosum. Fine needle aspiration cytology led to a diagnosis of granulomatous mastitis. Oral prednisolone rapidly improved the arthritis and the erythema nodosum. Granulomatous mastitis is a very rare, chronic inflammatory disease and only ten patients with granulomatous mastitis with erythema nodosum and polyarthitis have been described.
\end{abstract}

Key words: Erythema nodosum; Rheumatology; Arthritis.

Reumatismo, 2016; 68 (2): 97-99

\section{INTRODUCTION}

diopathic granulomatous mastitis (IGM) is a rare benign inflammatory disease of the breast, commonly affecting women in the reproductive age group. Patients typically present with a firm breast mass, associated with inflammation of the overlying skin. Nipple retraction, peau d'orange-like changes, and axillary adenopathy may be present. Extramammary manifestations of IGM are extremely rare. We report a rare association of IGM with erythema nodosum and polyarthritis in a 25 year-old female, who was successfully treated with systemic glucocorticoids.

\section{CASE REPORT}

A 25 year-old woman presented with pain and swelling in the left breast for one month with yellowish discharge from nipple. Three weeks later she developed bilateral pain, swelling and redness of ankles, knees, elbows, wrists and proximal interphalangeal joints with low-grade fever. She also noticed painful red nodules in the anterior aspect of both legs and forearm. Examination showed tender axillary lymphadenopathy, erythematous palpable discrete nodules over both limbs and fore- arm and a swelling of $5 \times 4 \mathrm{~cm}$ in the inner upper quadrant of the left breast, which was tender and firm. Hemoglobin was $10.5 \mathrm{gm} \%$ (normocytic normochromic), total leucocyte count 12,700 cells/mm3, with $79 \%$ neutrophils, platelet 3.2 Lakhs/ $\mathrm{mm} 3$ and erythrocyte sedimentation rate $64 \mathrm{~mm} / 1 \mathrm{st} \mathrm{hr}$. Renal function tests, liver function tests, and urinaysis were all normal. Her blood culture revealed no growth and chest radiography was normal. Fine needle aspiration cytology of the breast swelling showed collection of epitheloid cells, multinucleated giant cells and noncaseous granuloma (Figure 1).

No organisms were seen on gram, and acid-fast bacilli stainings. Fungal, mycobacteria tuberculosis (TB) and atypical mycobacteria cultures were negative. Tuberculin skin test was negative.

Anti-citrullinated cyclic peptide, antinuclear antibody, $\mathrm{P}$ and $\mathrm{C}$ antineutrophil cytoplasmic antibodies were all negative. Serum angiotensin converting enzyme level and serum calcium were normal. Causes of granulomatous breast disease, such as TB, fungal infections, sarcoidosis, Wegener granulomatosis were ruled out. Thus, a diagnosis of IGM with erythema nodosum and polyarthritis was made and she was started on oral corticoste-
Corresponding author Jemshad Alungal

Department of General Medicine Muslim Educational Society, Medical College,

P.O., Malaparamba, Kolathur Malappuram, Kerala 679338, India E-mail: jemshadalunga|@gmail.com 


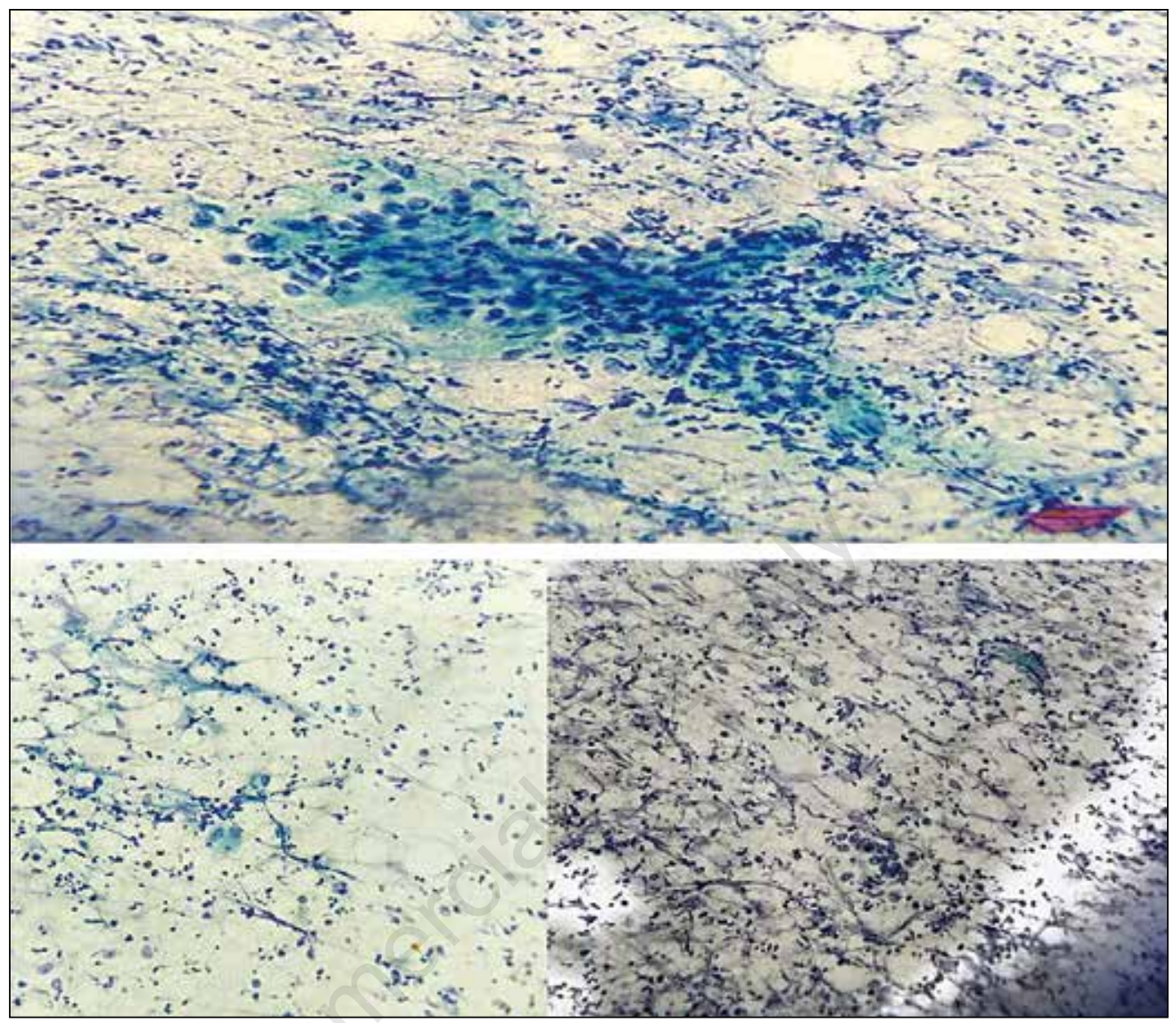

Figure 1 - Photomicrograph of the breast tissue showing a non-caseous granuloma composed of epithelioid cells and multinucleated giant cells (Papanicolaou stain 40x).

roids. When she returned for review after one month she was symptom-free and a follow-up ultrasonogram of the breast showed a significant decrease in size of the breast lump.

\section{DISCUSSION AND CONCLUSIONS}

IGM is a very rare disease that was originally reported by Kessler and Wolloch in 1972 (1). It is a rare benign inflammatory disease of women in the reproductive age group that may clinically mimic breast carcinoma (2). The diagnosis is by exclusion of other causes of granulomatous inflammation by special stains in tissue sections and by microbiological investigation.

Granulomas in the breast are caused by a wide variety of diseases, all present in less than $1 \%$ of the breast biopsies (3). Two types of IGM are identified: idiopathic and specific. Specific granuloma may be seen in TB, mycotic infections parasitic infestations and sarcoidosis (4). The distribution of granulomas, caseation necrosis, fungal special stains and serological tests help to differentiate these conditions. The presence of an exclusively granulomatous inflammatory reaction with neither caseous necrosis nor any specific organism and the presence of numerous epithelioid cells as well as the multinucleated Langerhanstype giant cells, neutrophils, lymphocytes, and stromal cells will confirm the diagnosis of IGM (5).

The mechanism of development of IGM is believed to involve the following sequence: ductal epithelial damage, transition of luminal secretions to the lobular connective tissue, local inflammation in connective tissue, macrophage and lym- 
phocyte migration to the region, and local granulomatosis inflammatory response (6). However, the trigger factor in the development of epithelial damage has not been clarified. Autoimmunity, pregnancy, lactation, hyperprolactinemia, oral contraceptive use, local trauma to the breast, smoking, are believed to be trigger factors in IGM etiology (7).

Polyarthritis and erythema nodosum are rare systemic manifestations of granulomatous mastitis. In 1987, Adams and colleagues reported the first case of granulomatous mastitis complicated by arthritis and erythema nodusum (8). Although cases of granulomatous mastitis complicated solely by erythema nodusum are occasionally reported, as far as we know, only ten other cases of granulomatous mastitis complicated by both arthritis and erythema nodosum have been previously reported. Response of IGM to steroids (9), and the occurrence of extramammary involvement such as erythema nodosum or arthritis support an autoimmune component in the etiology.

In endemic TB regions like our country, a painful breast mass with systemic manifestations like erythema nodosum and arthritis is suggestive of a diagnosis of breast TB. Diagnosis should be confirmed by histopathological findings, culture as well as molecular detection of mycobacterium TB using polymerase chain reaction.

Complete resection or open biopsy and corticosteroid therapy are the choice of treatment for IGM. Our patient was started on oral steroids and had marked improvement in her symptoms and reduction in the size of breast lump.

Conflict of interest: the authors declare no potential conflict of interest.

\section{REFERENCES}

1. Altintoprak F, Kivilcim T, Ozkan OV. Aetiology of idiopathic granulomatous mastitis. World J Clin Cases. 2014; 2: 852-8.

2. Mona A, Al Nazer. Idiopathic granulomatus lobular mastitis: a forgotten clinical diagnosis. Saudi Med J. 2003; 24: 1377-80.

3. Elsiddig KE, Khalil EA, Elhag IA, et al. Granulomatous mammary disease: ten years' experience with fine needle aspiration cytology. Int J Tuberc Lung Dis. 2003; 7: 365-9.

4. Binesh F, Kargar S, Zahir ST, et al. Idiopathic granulomatous mastitis, a clinicopathological review of 22 cases. J Clin Exp Pathol. 2014; 4: 157.

5. Altintoprak F, Karakece E, Kivilcim T, et al. Idiopathic granulomatous mastitis: an autoimmune disease? Sci World J. 2013; 2013: 148727.

6. Schelfout K, Tjalma WA, Cooremans ID, et al. Observations of an idiopathic granulomatous mastitis. Eur J Obstet Gynecol Reprod Biol. 2001; 97: 260-2.

7. Taylor GB, Paviour SD, Musaad S, et al. A clinicopathological review of 34 cases of inflammatory breast disease showing an association between corynebacteria infection and granulomatous mastitis. Pathology. 2003; 35 : 109-19.

8. Adams DH, Hubscher SG, Scott DG. Granulomatous mastitis: a rare cause of erythema nodosum. Postgrad Med J. 2003; 63: 581-2.

9. Pandey TS, Mackinnon JC, Bressler L, et al. Idiopathic granulomatous mastitis: a prospective study of 49 women and treatment outcomes with steroid therapy. Breast J. 2014; 20 : 258-66. 